\title{
Risk Factors for Work-related Injuries among University Student Employees
}

\author{
Judy $\mathrm{OU}^{1}$ and Steven M. THYGERSON ${ }^{2 *}$ \\ ${ }^{1}$ Department of Environmental Health, Boston University, USA \\ ${ }^{2}$ Department of Health Science, College of Life Sciences, Brigham Young University, USA \\ Received October 22, 2010 and accepted June 12, 2012 \\ Published online in J-STAGE August 8, 2012
}

\begin{abstract}
This study identified contributing risk factors in the occurrence of work-related injuries among university students employed at a single university. Four hundred seventy-six student employees completed the survey in March 2010. The majority of respondents were female (66\%) and the average age of all respondents was $20.7 \mathrm{yr}$. A pre-validated survey instrument was taken from the Youth Employment and School Study (YESS) and contained scales for the risk factors of interest. Results show significant differences in the amount of work-school conflict, boredom, workplace hazards, and workload between injured and non-injured groups. Odds ratios show that physical hazards and heavy workload have a significant two-fold increase on the likelihood of 1-3 injuries $(O R=1.80,1.09-3.00 ; O R=1.72,1.12-2.60)$, and a 2 to 3 fold increase in 4 or more injuries $(O R=2.94$, 1.65-5.24; $\mathrm{OR}=2.34,1.51-3.64)$. Good supervisor relations appear to reduce injury risk $(\mathrm{OR}=0.48$, $0.25-0.91 ; O R=0.59,0.32-1.09)$. Reducing workload stress, teaching students how to manage the workload, reducing exposure to physical hazards, and providing examples of standard work practices may reduce the number of injuries seen in the population.
\end{abstract}

Key words: Student employees, Injuries, Occupational health and safety, Risk factors

\section{Introduction}

Occupational injuries are a burden to employees and employers. The Bureau of Labor Statistics reports that 3.1 million nonfatal workplace injuries occurred in private industry employers in 2010, with an incidence rate of 3.5 cases per 100 full-time employees ${ }^{1}$. Injuries can be linked to risk factors such as stress, fatigue, repetition, and workload. Stress, both work and non-work related, has been implied to increase the risk of mental and physical health problems ${ }^{2)}$. Injured workers are more likely to report a higher stressors frequency $(\mathrm{OR}=1.4(0.9-2.0))$, resulting

*To whom correspondence should be addressed.

E-mail: steven.thygerson@byu.edu

(C)2012 National Institute of Occupational Safety and Health in a monotonic dose-response relationship between stress reaction and injury $(p=0.02)^{3)}$. Workers with problems in their interpersonal relationships $(\mathrm{RR}=1.43 ; 1.18-1.73)$ or coworker relationships $(\mathrm{RR}=1.40 ; 1.15-1.71)$ also report greater risk for injury ${ }^{4)}$. Specifically, supervisor conflict $(\mathrm{RR}=2.49$ (1.42-4.37)), coworker conflict $(\mathrm{RR}=2.62$; $0.58-4.35)$, and high emotional demands $(R R=2.45$; 1.52-3.94) increased injury risk ${ }^{5}$. Further epidemiologic research divided risk factors into human (demographics, job title, experience), job content (task design, tasks organization, job schedules), and environmental categories (physical hazards) ${ }^{6}$.

Occupational injuries among university student employees have not been studied. University students may be at higher risk for injury than the general adult population due to their younger age and lack of experience or training ${ }^{7}$, ${ }^{8)}$. Poor working conditions and stress or fatigue from 
balancing school and work may also increase their risk for injury ${ }^{5,9)}$.

Injuries sustained during the early twenties may have severe economic, physical, and mental impacts later in life. Workers compensation records show that adults aged 20-24 yr had a significantly higher risk for injury than older adults ${ }^{10-12)}$. Injury rates peak in young men aged 18-24 years, the age range of most employed university students ${ }^{11)}$.

This cross-sectional study identifies the risk factors for injury in students enrolled at a single university, employed in the three departments with the largest number of student employees (grounds, custodial and building maintenance). The university has 32,000 full-time students and approximately 13,000 university student employees per semester.

\section{Methods}

A pre-validated survey instrument was taken from the Youth Employment and School Study (YESS), and adapted for use by Frone for use with employed adolescents. The YESS contained scales for the risk factors of interest. The risk factors used in the survey included exposure to workplace hazards (alpha coeff $=0.79$ ), workload (alpha coeff $=0.69$ ), work-school conflict (alpha coeff $=0.86$ ), supervisor relations (alpha coeff $=0.79$ ), and boredom (alpha coeff $=0.80)^{13)}$.

Since surveying the entire working student population was not feasible, the survey was administered in departments with the largest number of employed students. These departments also had the most filed workers compensation claims over a five-year period. The Institutional Review Board at the university approved this study, but IRB did not allow us to survey student drinking and drug use.

Students were emailed a link to the survey via Qualtrics, a website specializing in online surveys, through their respective department managers. A raffle ticket to win a $\$ 20$ gift card was provided as an incentive to participate.

Results were analyzed using Statistical Analytical Software (SAS). Results from the risk factor scales for workload, job boredom, supervisor relations, and workschool conflict were scored using as the key dictated by the instrument. Significant differences in risk factor scores were determined using $t$-tests. Stepwise logistic regression was used to obtain odds ratios, controlling for age, sex, and job tenure. Missing data was not included in the regression analysis. Students reported no injuries were used as controls; students who reported one or more workplace injuries were considered cases.
Table 1. Characteristics of university student employees

\begin{tabular}{|c|c|c|c|}
\hline & All & Injured & Non-Injured \\
\hline \multicolumn{4}{|l|}{ Sex, \# (\%) } \\
\hline Female & $315(66.2)$ & $114(74.5)$ & $190(61.5)$ \\
\hline Male & $161(33.8)$ & $39(25.49)$ & $119(38.5)$ \\
\hline Total & 476 & 153 & 309 \\
\hline \multicolumn{4}{|l|}{ Age distribution, $\%$} \\
\hline 17-19 years & 35.29 & 32.03 & 35.6 \\
\hline $20-23$ & 52.1 & 50.32 & 53.72 \\
\hline $24-26+$ & 12.64 & 17.65 & 10.68 \\
\hline Total & 100 & 100 & 100 \\
\hline \multicolumn{4}{|l|}{ Job Tenure, $\%$} \\
\hline Less than one month & 2.1 & 0.65 & 2.91 \\
\hline $1-3$ months & 19.54 & 9.15 & 24.27 \\
\hline 4-6 months & 19.54 & 13.07 & 22.33 \\
\hline 7-9 months & 19.12 & 22.88 & 17.48 \\
\hline $10-12$ months & 5.67 & 6.54 & 5.18 \\
\hline more than one year & 34.03 & 47.71 & 27.83 \\
\hline Total & 100 & 100 & 100 \\
\hline \multicolumn{4}{|c|}{ Risk Factor Scores $(\mathrm{Max}=5.0)$} \\
\hline Heavy Workload & 2.71 & $3.19 *$ & $2.52 *$ \\
\hline Workplace Hazards & 2.11 & $2.32 *$ & $1.95^{*}$ \\
\hline Work-school Conflict & 2.47 & $2.62 *$ & $2.42 *$ \\
\hline Boredom & 2.87 & $2.73 *$ & $2.95 *$ \\
\hline Supervisor & 1.28 & 1.4 & 1.23 \\
\hline
\end{tabular}

* Significant $\chi^{2}$ at $p=0.05$.

\section{Results}

A total of 153 injuries occurred in the 476 surveyed student employees, resulting in an injury prevalence of 32 per 100 student employees, and an incidence rate is 4.2 per 100 person months. As expected in a university aged population, the majority of students were between 20 and $23 \mathrm{yr}$, with an average age of $20.7 \mathrm{yr}$. A third of students had been employed at their jobs for more than a year (see Table 1).

Odds ratios show that physical hazards, and a heavy workload result in a near two-fold increased risk for injury (Table 2) Being exposed to a heavy workload and physical hazards increases likelihood of injury, but also the number of injuries. Findings were not significant for work-school conflict and boredom. Since the scores for supervisor relations showed that worker-supervisor relations were generally good, the odds ratios show that good relations may be protective against injury (Table 2 ).

Table 3 shows the results for the model fit. The model for one to three injuries is not as well-fitting as the model for four or more injuries, which suggests that the risk factors may be better predictors of more frequent injuries. 
Table 2. Risk Factor OR for Injuries

\begin{tabular}{|c|c|c|c|}
\hline Risk Factor & Injury Frequency & OR & $95 \% \mathrm{CI}$ \\
\hline \multirow[t]{3}{*}{ Heavy Workload } & No Injuries & 1 & \\
\hline & 1-3 Injuries & $1.71 *$ & $1.12-2.60$ \\
\hline & $\geq 4$ Injuries & $2.34 *$ & $1.51-3.64$ \\
\hline \multirow[t]{3}{*}{ Work-school Conflict } & No Injuries & 1 & \\
\hline & 1-3 Injuries & 0.83 & $0.56-1.24$ \\
\hline & $\geq 4$ Injuries & 1.16 & $0.73-1.84$ \\
\hline \multirow[t]{3}{*}{ Physical Hazards } & No Injuries & 1 & \\
\hline & 1-3 Injuries & $1.80 *$ & $1.09-3.00$ \\
\hline & $\geq 4$ Injuries & $2.94 *$ & $1.65-5.24$ \\
\hline \multirow[t]{3}{*}{ Supervisor Conflict } & No Injuries & 1 & \\
\hline & 1-3 Injuries & $0.48 *$ & $0.25-0.91$ \\
\hline & $\geq 4$ Injuries & 0.59 & $0.32-1.09$ \\
\hline \multirow[t]{3}{*}{ Boredom } & No Injuries & 1 & \\
\hline & 1-3 Injuries & 1.09 & $0.73-1.61$ \\
\hline & $\geq 4$ Injuries & 0.76 & $0.50-1.17$ \\
\hline
\end{tabular}

* Significant $\mathrm{OR}$ at $\mathrm{p}=0.05$.

Odds Ratios (OR) adjusted for age, job tenure, and sex.

\section{Discussion}

This study used a cross-sectional survey to study occupational and personal factors that place this young working population at risk. Previous studies have not specifically focused on this working population, although past studies provide evidence to suggest that university student employees may have unique working and lifestyle situations that separate them from the general adult population.

Data obtained from this survey found that this young working population had a non-fatal injury incidence rate of (4.2 per 100 person months). We cannot compare this to the national incidence rate of 3.5 per 100 full-time workers, because we were unable to obtain the actual number of hours worked per year. The average age of the population is $20.7 \mathrm{yr}$, which is drastically younger than the general adult working population. The high prevalence and incidence rate of injuries could be a product of inexperience at work and a lack of standard work practices.

Greater exposure to workplace hazards and a heavy workload were closely associated with a greater risk for injury. This finding supports past studies on adult occupational injuries that found a significant relationship between workplace stressors and injury ${ }^{2,3)}$. University students who experience heavy workloads have a two-fold increased risk for multiple injuries, and an increased risk for lacerations (Table 2). Students exposed to workplace hazards also have a significant increased risk for multiple injuries, particularly strains, lacerations, and bruises (Table 2). The increased odds ratios imply that a dose-response relationship may exist between workload and injury, and physical hazards and injury (Table 3 ). This finding is consistent with previous research by Li et $a l^{3}$.

This study found null effects for boredom on injury, but found a preventive effect of good supervisor relations with injury risk (Table 1). This preventive effect agrees with past findings that interpersonal relations at work affect total injury risk ${ }^{4,5)}$.

University risk management and department managers could focus on reducing the number of on-site physical hazards, such as reducing exposure to chemical hazards and heavy machinery. Reducing the stress level of the workload, teaching students how to manage the workload, and providing examples of standard work practices may reduce the number of injuries seen in the population.

Table 3. Risk Factor OR for Injury by Injury Type

\begin{tabular}{|c|c|c|c|c|c|c|c|}
\hline \multirow{2}{*}{ Risk Factor } & \multirow{2}{*}{ Injury Frequency } & \multicolumn{2}{|c|}{ Strains/Sprains } & \multicolumn{2}{|c|}{ Cuts/Lacerations } & \multicolumn{2}{|c|}{ Bruises/Contusions } \\
\hline & & OR & $95 \% \mathrm{CI}$ & OR & $95 \% \mathrm{CI}$ & OR & $95 \% \mathrm{CI}$ \\
\hline \multirow[t]{2}{*}{ Heavy Workload } & No Injuries & 1 & & 1 & & 1 & \\
\hline & $1+$ Injuries & 1.25 & $0.91-1.71$ & $1.83^{*}$ & $1.35-2.47$ & 1.26 & $0.94-1.68$ \\
\hline \multirow{2}{*}{ Work-school Conflict } & No Injuries & 1 & & 1 & & 1 & \\
\hline & 1+ Injuries & 1.25 & $0.90-1.75$ & 0.92 & $0.67-1.26$ & $1.9^{*}$ & $1.38-2.61$ \\
\hline \multirow[t]{2}{*}{ Physical Hazards } & No Injuries & 1 & & 1 & & 1 & \\
\hline & $1+$ Injuries & $1.94 *$ & $1.34-2.80$ & $1.82 *$ & $1.25-2.64$ & 1.56 & $1.09-2.22$ \\
\hline \multirow[t]{2}{*}{ Supervisor Relations } & No Injuries & 1 & & 1 & & 1 & \\
\hline & $1+$ Injuries & 1.23 & $0.78-1.92$ & 0.87 & $0.54-1.40$ & 0.64 & $0.43-1.03$ \\
\hline \multirow[t]{2}{*}{ Boredom } & No Injuries & 1 & & 1 & & 1 & \\
\hline & $1+$ Injuries & $0.60 *$ & $0.43-0.82$ & 1.01 & $0.76-1.35$ & $0.64 *$ & $0.48-0.86$ \\
\hline
\end{tabular}

* Significant OR at $p=0.05$. Odds Rations (OR) adjusted for age, job tenure, and sex. 
Safety education should also focus more on influencing safety beliefs, which may be a better predictor of safe behavior than other factors ${ }^{14)}$. Additionally, research supports safety training that develops empowerment skills and links knowledge with safe behavior ${ }^{15}$.

An unexpected finding was the large number of students that had worked at their jobs for a longer tenure. Although the managers stated that six weeks was the average length of tenure, $59 \%$ of surveyed employees worked in their departments for over six months. Only $22 \%$ worked in their positions for three months or less.

Students with longer job tenure also reported a high number of cumulative injuries, which could indicate a casual attitude toward safe work practices. Studies have shown a tendency for college students to be less safety conscious from one decade to the next in terms of health and safety behaviors such as wearing a bicycle helmet and use of tobacco products ${ }^{11,16)}$. This leads us to ask the question if longer tenure at the same job leads to a less safetyconscious worker, especially among university student employees. Future studies should focus on this question and findings from this study.

\section{Limitations}

The survey was only distributed at one university in three specific departments, limiting generalizabilty about the university student employee population. Information about more desk oriented work is not known, as this study focused on students that worked in more physically demanding jobs. The actual number of hours worked per student could not be determined, which limits our ability to compare the incidence rate we obtained with national incidence statistics. However, the researchers were also not allowed to ask questions about drug and alcohol use due to complications with student privacy and university policies. Most students at this university abstain from alcohol and drug use for religious reasons. Students are also required to sign an honor code prohibiting alcohol and drug use while enrolled at the university. Asking for personal information and alcohol use was perceived as threatening to student enrollment. However, our inability to control for confounding due to alcohol and drug use limits the generalizabilty of the findings. The significant differences in the risk factor scores between injured and non-injured students could be attributed to sample size rather than actual differences in scores.

The study is also subject to self-selection and differential participation, in which greater proportions of injured students would enroll in the survey. However, twice as many non-injured students as injured students participated in the study, which reduces this bias. Injury reporting was done on a self-report basis, and could not be verified using workers compensation data. The study may also suffer from differential dependent misclassification, where injured students are more likely to report adverse risk factor scores than non-injured populations. This would bias the results upward. This cross sectional survey can only provide information about injuries from a specific point in time. We cannot discuss likelihood of injury over time, nor can we quantify any past exposures that may have increased student risk for injury. Although this survey provides some information about student employee injuries and risk factors for injury, more information needs to be gathered about this working population.

Although the study is limited, the study identified the incidence of and risks for injury in this specialized population. We identified an injury rate of 4.2 per 100 person months for university student employees. The findings also agree with past literature that identifies the role of work-related stressors on injury risk. In university students, workload and the presence of physical hazards significantly contribute to risk for multiple injuries. Having good supervisor relations may prevent injuries, which may be an indicator of how interpersonal work relations and communication affect risk for injury. Risk for injury would be reduced through limiting exposure to physical hazards. Reducing the stress level of the workload, teaching students how to manage the workload, and providing examples of standard work practices may also reduce the number of injuries seen in the population.

\section{References}

1) Bureau of Labor Statistics, U.S. Department of Labor. Workplace Injuries and Illnesses - 2010. http://www.bls. gov/news.release/pdf/osh.pdf. Accessed January 20, 2012.

2) Karasek R, Theorell T (1990) Healthy work. Basic Books, New York.

3) Li CY, Chen KR, Wu CH, Sung FC (2001) Job stress and dissatisfaction in association with non-fatal injuries on the job in a cross-sectional sample of petrochemical workers. Occup Med(Lond) 51, 50-5. [Medline] [CrossRef]

4) Salminen S, Kivimäki M, Elovainio M, Vahtera J (2003) Stress factors predicting injuries of hospital personnel. Am J Ind Med 44, 32-6. [Medline] [CrossRef]

5) Swaen GM, van Amelsvoort LG, Bultmann U, Slagen JJM, Kant IJ (2003) Fatigue as a risk factor for being injured in an occupational accident: results from the Maastricht Cohort Study. Occup Environ Med 60 (Suppl 1), i88-92. 
[Medline] [CrossRef]

6) Veazie MA, Bender TR, Amandus HE (1994) Epidemiologic research on the etiology of injuries at work. Annu Rev Public Health 15, 203-21. [Medline] [CrossRef]

7) Breslin C, Koehoorn M, Smith P, Manno M (2003) Age related differences in work injuries and permanent impairment: a comparison of workers' compensation claims among adolescents, young adults, and adults. Occup Environ Med 60, E10. [Medline] [CrossRef]

8) Wong TW (1994) Occupational injuries among construction workers in Hong Kong. Occup Med Oxf 44, 247-52. [Medline] [CrossRef]

9) Melamed S, Yekutieli D, Froom P, Kristal-Boneh E, Ribak J (1999) Adverse work and environmental conditions predict occupational injuries. The Israeli Cardiovascular Occupational Risk Factors Determination in Israel (CORDIS) Study. Am J Epidemiol 150, 18-26. [Medline] [CrossRef]

10) Breslin FC, Smith P (2006) Trial by fire: a multivariate examination of the relation between job tenure and work injuries. Occup Environ Med 63, 27-32. [Medline] [CrossRef]

11) Smith GS, Wellman HM, Sorock GS, Warner M, Courtney
TK, Pransky GS, Fingerhut LA (2005) Injuries at work in the US adult population: Contributions to the total injury burden. Am J Public Health 95, 1213-9. [Medline] [CrossRef]

12) Salminen $S$ (2004) Have young workers more injuries than older ones? An international literature review. J Safety Res 35, 513-21. [Medline] [CrossRef]

13) Frone MR (1998) Predictors of work injuries among employed adolescents. J Appl Psychol 83, 565-76. [Medline] [CrossRef]

14) Blair EH, Seo D, Torabi MR, Kaldahl MA (2004) Safety beliefs and safe behavior among midwestern college students. J Safety Res 35, 131-40. [Medline] [CrossRef]

15) Thamrin Y, Pisaniello D, Stewart S (2010) Time trends and predictive factors for safety perceptions among incoming South Australian university students. J Safety Res 41, 59-63. [Medline] [CrossRef]

16) Steptoe A, Wardle J, Cui W, Bellisle F, Zotti AM, Baranyai R, Sanderman R (2002) Trends in smoking, diet, physical exercise, and attitudes toward health in European university students from 13 countries. Prev Med 35, 97-104. [Medline] [CrossRef] 